\title{
Uréia em dietas para bovinos: consumo, digestibilidade dos nutrientes, ganho de peso, características de carcaça e produção microbiana ${ }^{1}$
}

\section{Mônica Lopes Paixão², Sebastião de Campos Valadares Filho ${ }^{3^{*}}$, Maria Ignez Leão ${ }^{3}$, Rilene Ferreira Diniz Valadares ${ }^{4^{\star}}$, Mário Fonseca Paulino ${ }^{3^{*}}$, Marcos Inácio Marcondes ${ }^{5}$, Mozart Alves Fonseca6, Polyana Albino Silva ${ }^{2}$, Douglas dos Santos Pina ${ }^{2}$}

\author{
1 Parte da tese de Mestrado da primeira autora parcialmente financiada pela FAPEMIG. \\ 2 Doutorando em Zootecnia - UFV. \\ ${ }^{3}$ DZO/UFV. \\ 4 DVT/UFV. \\ ${ }^{5}$ Mestrando em Zootecnia - UFV. \\ 6 Graduando em Agronomia - UFV. Bolsista IC/CNPq. \\ * Bolsista CNPq.
}

RESUMO - Objetivou-se determinar o efeito da substituição total da proteína do farelo de soja pelo nitrogênio nãoprotéico da uréia, em dois níveis de oferta de concentrado, sobre o ganho de peso, as características de carcaça, os consumos e as digestibilidades totais dos nutrientes (MS, MO, PB, EE, FDN e CNF) e o consumo de NDT. Avaliou-se também o efeito da substituição sobre a eficiência de síntese microbiana em 16 novilhos (286 kg de PV inicial) em confinamento durante 63 dias. Os animais foram distribuídos em um esquema fatorial 2 x 2, com duas fontes protéicas (farelo de soja e uréia) e dois níveis de concentrado ( 0,75 e $1,25 \%$ do PV), em delineamento inteiramente casualizado com quatro repetições. As rações, isoprotéicas (12\% PB), foram compostas de silagens de capim-elefante e de sorgo como volumoso, na proporção de 80:20, respectivamente. A eficiência de síntese microbiana não foi afetada pelos tratamentos. Os consumos de MS, MO, EE, FDN, CNF e NDT, assim como as digestibilidades aparentes totais de MS, MO, EE e NDT, aumentaram com os níveis de oferta de concentrado. A fonte protéica não afetou os consumos e as digestibilidades dos nutrientes estudados, exceto o EE. Aumentos na oferta de concentrado resultam em maior consumo de energia e mais alto ganho de peso. A substituição do farelo de soja pela uréia não altera o ganho de peso de bovinos com potencial genético para ganho de 1,1-1,2 kg/dia.

Palavras-chave: concentrado, confinamento, desempenho, novilhos, nitrogênio não-protéico

\section{Urea in diets of steers: intake, digestibility, performance, carcass traits and microbial yield}

\begin{abstract}
The objective of this trial was to evaluate the effects of replacing soybean meal with urea on performance, carcass traits, and intake and digestibility of nutrients in steers. Microbial protein synthesis and efficiency were also measured in this trial. Sixteen steers averaging $286 \mathrm{~kg}$ of BW were assigned to a completely randomized design with a $2 \times 2$ factorial approach: two protein sources (soybean meal and urea) and two levels of concentrate ( 0.75 and $1.25 \%$ of $\mathrm{BW})$; four replicates per treatment were used and the experiment lasted 63 days. Diets were isonitrogenous (12\% of CP) with the forage portion composed by elephant grass silage and sorghum silage in the ratio of 80:20. Efficiency of microbial protein synthesis was not affected by treatments. Intakes of DM, OM, EE, NDF, NFC and TDN and apparent total tract digestibilities of DM, OM, EE and TDN all increased linearly when the proportion of concentrate was increased in the diet. Except for EE, the protein sources did not affect the intake and digestibility of all remaining nutrients. Feeding high concentrate diets to steers increased energy intake and improved performance. Replacing soybean meal with urea did not change the average daily gain of steers with expected BW gain varying from 1.1 to $1.2 \mathrm{~kg} /$ day.
\end{abstract}

Key Words: concentrate, feedlot, non-protein nitrogen, performance, steers

\section{Introdução}

A proteína é o ingrediente de maior custo unitário nas rações e, por isso, deve merecer maior atenção. A substituição da proteína do farelo de soja pelo nitrogênio não-protéico
(NNP) da uréia em dietas para ruminantes é possível somente em virtude da capacidade dos microrganismos ruminais de converter o NNP em proteína de alto valor biológico.

Quanto aos níveis de substituição, a recomendação tradicionalmente adotada pela maioria dos pesquisadores é 
a de que o NNP pode substituir até 33\% do nitrogênio protéico da dieta de ruminantes (Velloso, 1984). Tem-se sugerido ainda limitar a quantidade de uréia em até $1,0 \%$ na MS total da dieta (Haddad, 1984). Entretanto, maiores níveis de inclusão de uréia têm sido utilizados sem que haja comprometimento do desempenho dos animais (Valadares et al., 2004). Dessa forma, o nível máximo de inclusão de uréia nas rações e seus efeitos sobre a síntese microbiana, o consumo, a degradabilidade da dieta, o ganho de peso e as características de carcaça ainda não estão totalmente definidos.

A maior parte do nitrogênio utilizado pelos microrganismos ruminais encontra-se na forma de amônia e as bactérias são eficientes em assimilar amônia até satisfazer seus requerimentos, deteminados pela disponibilidade de carboidratos fermentáveis. A amônia em excesso é absorvida pela parede do rúmen e, no fígado, é convertida a uréia. Esta conversão custa ao animal $12 \mathrm{kcal} / \mathrm{g}$ de nitrogênio (Van Soest, 1994). A excreção de uréia representa elevado custo biológico e desvio de energia para a manutenção das concentrações corporais de nitrogênio em níveis não tóxicos.

Além do conhecimento do consumo e da composição bromatológica dos alimentos, é importante obter informações sobre a utilização dos nutrientes pelo animal, por meio de estudos da digestão. De acordo com Coelho da Silva \& Leão (1979), digestibilidade é característica do alimento e indica a porcentagem de cada nutriente de um alimento que o animal pode utilizar. Contudo, a inclusão de um ingrediente em determinada ração pode modificar sua digestão, como resultado do efeito associativo entre os alimentos (Coelho da Silva \& Leão, 1979; Moore et al., 1997). Neste sentido, Faria \& Huber (1984) e Hennessy et al. (1995) realizaram ensaios e não notaram influência da suplementação com uréia na dieta sobre a digestibilidade da MS em novilhos.

$\mathrm{O}$ rendimento de carcaça pode ser afetado por fatores como peso do conteúdo gastrintestinal, que é diretamente afetado pelo número de horas de jejum a que os animais são submetidos, pelo tipo de dieta, pelo peso e/ou a idade de abate e pelo grau de engorda, além dos pesos do couro, da cabeça e do trato gastrintestinal. Os cortes básicos das carcaças de bovinos no mercado brasileiro são o dianteiro, com cinco costelas, a ponta-de-agulha e o traseiro especial. Economicamente, é desejável maior rendimento do traseiro especial em relação aos outros cortes, pois nele se encontram as partes nobres da carcaça, de maior valor comercial.

Diante do exposto, os objetivos neste trabalho foram avaliar o efeito de dois níveis de concentrado $(0,75$ e $1,25 \%$ do PV) e de dois níveis de substituição da proteína do farelo de soja pelo nitrogênio não-protéico da uréia (0 e 100\%) sobre os consumos e as digestibilidades dos nutrientes, as características físicas da carcaça e os rendimentos de cortes básicos e estimar a produção de proteína microbiana utilizando-se a excreção dos derivados de purina na urina.

\section{Material e Métodos}

O experimento foi conduzido no Laboratório de Animais e no Laboratório de Nutrição Animal do Departamento de Zootecnia do Centro de Ciências Agrárias da Universidade Federal de Viçosa, em Viçosa - MG, e a fase de campo realizada no período de julho a outubro de 2003.

Foram confinados 16 animais (quatro Nelores e $12 \mathrm{com}$ grau de sangue predominantemente Holandês) com $286 \mathrm{~kg}$ de PV inicial durante 63 dias, adaptados previamente durante 14 dias. Os animais foram alojados em baias individuais com piso de concreto, providas de comedouro, bebedouro e cocho para sal, com área em confinamento de $30 \mathrm{~m}^{2}$ ( $8 \mathrm{~m}^{2}$ cobertos com telhas de amianto).

Os animais foram distribuídos em um esquema fatorial $2 \times 2$, com duas fontes protéicas (farelo de soja e uréia) e dois níveis de oferta de concentrado ( 0,75 e 1,25\% do PV), em um delineamento inteiramente casualizado com quatro repetições. As rações foram formuladas para serem isoprotéicas, com aproximadamente $12 \% \mathrm{~PB}$.

O volumoso foi fornecido à vontade, uma vez ao dia às $7 \mathrm{~h}$, sendo constituído de silagens de capim-elefante e de sorgo na proporção de 80:20, com base na MS. Foram feitas anotações diárias tanto da quantidade de ração fornecida quanto das sobras para cada animal, além de amostragens das silagens e das sobras. As amostras diárias foram agru padas em amostras semanais, que constituíram uma amostra composta para cada período experimental. Os ingredientes dos concentrados (farelo de soja e milho) foram amostrados antes de se proceder à mistura das rações e às análises laboratoriais.

$\mathrm{Na}$ Tabela 1 constam a proporção dos ingredientes e a composição químico-bromatológica e, na Tabela 2 , a composição média das dietas experimentais.

As pesagens foram realizadas no início do experimento e a cada 21 dias, durante três períodos, para determinação do ganho médio diário de peso vivo (GMD), sendo precedidas de jejum alimentar de 16 horas.

As amostras spot de urina foram coletadas no 130 dia e as de fezes no 10 음 dia de manhã e no 15 o dia à tarde do $2 \underline{\text { o }}$ período experimental.

Os animais foram contidos no tronco e as amostras spot de urina foram coletadas 4 horas após a alimentação, por meio de massagem. Em seguida, a urina foi homogeneizada, filtrada e uma alíquota de $10 \mathrm{~mL}$ foi transferida para outro frasco contendo $40 \mathrm{~mL} \mathrm{de} \mathrm{H}_{2} \mathrm{SO}_{4}$ a 
Tabela 1 - Proporção dos ingredientes e teores de nutrientes dos concentrados e das silagens de capim-elefante e de sorgo, com base na MS

Table 1 - Ingredient and chemical compositions of the concentrates, elephantgrass silage and sorghum silage, \% of DM

\begin{tabular}{|c|c|c|c|c|c|c|}
\hline \multirow[t]{3}{*}{$\begin{array}{l}\text { Ingrediente }(\%) \\
\text { Ingredient }(\%)\end{array}$} & \multicolumn{2}{|c|}{$\begin{array}{c}\mathrm{C}=0,75 \% \mathrm{PV}^{4} \\
C=0.75 \% B W\end{array}$} & \multicolumn{2}{|c|}{$\begin{array}{c}\mathrm{C}=1,25 \% \mathrm{PV}^{4} \\
C=1.25 \% B W\end{array}$} & \multirow[t]{3}{*}{$\begin{array}{l}\text { Silagem de capim-elefante } \\
\text { Elephantgrass silage }\end{array}$} & \multirow[t]{3}{*}{$\begin{array}{l}\text { Silagem de sorgo } \\
\text { Sorghum silage }\end{array}$} \\
\hline & FS & $\mathrm{U}$ & FS & $\mathrm{U}$ & & \\
\hline & $S M$ & $U S$ & $M$ & $U$ & & \\
\hline Fubá de milho (Ground corn) & 46,80 & 89,30 & 71,80 & 94,24 & & \\
\hline Farelo de soja (Soybean meal) & 50,20 & - & 26,40 & - & & \\
\hline Uréia (Urea) & - & 7,00 & - & 3,60 & & \\
\hline Sulfato de amônia (Ammonium sulfate) & - & 0,70 & - & 0,36 & & \\
\hline Sal mineral (Mineral salt) & 3,00 & 3,00 & 1,80 & 1,80 & & \\
\hline \multirow{2}{*}{\multicolumn{7}{|c|}{$\begin{array}{l}\text { Composição química } \\
\text { Chemical composition }\end{array}$}} \\
\hline & & & & & & \\
\hline $\mathrm{MS}^{1}(D M)$ & 88,09 & 87,54 & 87,44 & 86,85 & 28,91 & 24,00 \\
\hline $\mathrm{MO}^{1}(O M)$ & 94,48 & 96,41 & 96,31 & 97,47 & 90,39 & 94,34 \\
\hline $\mathrm{PB}^{1}(C P)$ & 29,87 & 30,57 & 20,58 & 20,71 & 4,40 & 6,94 \\
\hline $\mathrm{NIDN}^{2}(N D I N)$ & 7,23 & 8,30 & 8,19 & 8,75 & 15,90 & 39,39 \\
\hline $\mathrm{NIDA}^{2}(A D I N)$ & 3,93 & 4,69 & 4,55 & 4,95 & 14,20 & 11,69 \\
\hline $\mathrm{EE}^{1}(E E)$ & 2,09 & 3,18 & 2,78 & 3,35 & 1,32 & 1,91 \\
\hline $\mathrm{NDT}^{3}(T D N)$ & 66,16 & 63,54 & 62,74 & 66,97 & - & - \\
\hline $\mathrm{CT}^{1}(T C)$ & 62,52 & 62,66 & 72,95 & 73,41 & 85,59 & 84,02 \\
\hline $\mathrm{FDN}^{1}(N D F)$ & 12,13 & 9,28 & 11,29 & 9,80 & 67,68 & 62,12 \\
\hline $\mathrm{FDNcp}^{1}($ NDFap) & 9,94 & 7,45 & 8,88 & 7,93 & 62,69 & 56,67 \\
\hline $\mathrm{CNF}^{1}(N F C)$ & 50,39 & 65,98 & 61,66 & 70,09 & 19,23 & 23,81 \\
\hline $\mathrm{FDA}^{1}(A D F)$ & 6,10 & 2,54 & 4,55 & 2,64 & 42,18 & 36,04 \\
\hline $\operatorname{Lignina}^{1}$ (Lignin) & 1,66 & 2,27 & 1,57 & 1,94 & 4,12 & 3,69 \\
\hline
\end{tabular}

$1 \% \mathrm{MS} ;{ }^{2} \%$ do $\mathrm{N}$ total; ${ }^{3}$ NDT observado, ${ }^{4}$ Peso vivo.

$1 \% D M ;{ }^{2} \%$ of total $N,{ }^{3}$ TDN observed $;{ }^{4}$ Body weight.

$\mathrm{C}=$ concentrado; $\mathrm{U}=$ tratamento contendo uréia e milho; FS = tratamento contendo farelo de soja e milho.

$C=$ concentrate $U=$ treatmen twith urea and corn; $S M=$ treatment with soybean meal and corn.

0,036 N para evitar destruição bacteriana dos derivados de purina e precipitação do ácido úrico. Devidamente identificadas, as amostras foram acondicionadas a $-15^{\circ} \mathrm{C}$.

Simultaneamente à coleta de urina, procedeu-se à amostragem de sangue, via punção na veia jugular. O sangue foi coletado em um tubo de ensaio contendo gel acelerador de coagulação e, em seguida, foi centrifugado a $2.000 \mathrm{rpm}$ durante 15 minutos, sendo o soro armazenado a $-15^{\circ} \mathrm{C}$.

As amostras de fezes e de sobras foram pré-secas em estufa de ventilação forçada, a $65^{\circ} \mathrm{C}$ por 72 horas, trituradas em moinho de facas com peneira de $1 \mathrm{~mm}$ e acondicionadas em vidros para posteriores análises laboratoriais.

Nas amostras de alimentos, sobras e fezes, foram determinados os teores de MS, MO, nitrogênio total (NT) e EE e, nas de alimentos, determinaram-se os teores de FDA, conforme Silva \& Queiroz (2002). A FDN foi determinada pela técnica da autoclave, segundo Pell \& Schofield (1993), sendo quantificados os teores de PB e cinzas da FDN, para determinação da FDN corrigida (FDNcp). Na FDA e FDN retidas no cadinho filtrante, foram determinados, respectivamente, os teores de nitrogênio insolúvel em detergente neutro (NIDN) e nitrogênio insolúvel em detergente ácido (NIDA), conforme Silva \& Queiroz (2002).
A fibra em detergente ácido indigestível (FDAi) foi utilizada como indicador interno, de acordo com metodologia descrita por Craig et al. (1984). Entretanto, utilizou-se a incubação ruminal em sacos de Ankom (filter bags, F57), por 144 horas, em vez da digestibilidade in vitro, sugerida no protocolo original. Foram incubadas amostras de alimentos, fezes e sobras. O material remanescente foi lavado em água e fervido em detergente ácido por 1 hora, sendo lavado novamente em água destilada e em acetona e seco em estufa a $65^{\circ} \mathrm{C}$ por 72 horas.

Em virtude da presença de uréia nas dietas, os CNF foram obtidos por meio da equação proposta por Hall (2000): $\mathrm{CNF}=100-[(\% \mathrm{~PB}-\% \mathrm{~PB}$ da uréia $+\%$ uréia $)+$ FDNcp $+\% \mathrm{EE}+\%$ Cinzas]; os carboidratos totais (CT) foram obtidos utilizando-se a equação: $100-(\% \mathrm{~PB}+\% \mathrm{EE}+$ \%cinzas) (Sniffen et al., 1992); e os nutrientes digestíveis totais (NDT) foram calculados como: NDT $=\%$ PBdigestível $+\%$ FDNdigestível +\%CNFdigestível + 2,25*\%EEdigestível.

Ao final do experimento, a urina foi descongelada à temperatura ambiente e analisada para determinação dos níveis de creatinina, segundo o método diacetil modificado com uso de picrato e acidificante, kit comercial (Labtest). 
Tabela 2 - Composição química das dietas experimentais, com base na MS

Table 2 - Chemical composition of the experimental diets, \% of DM

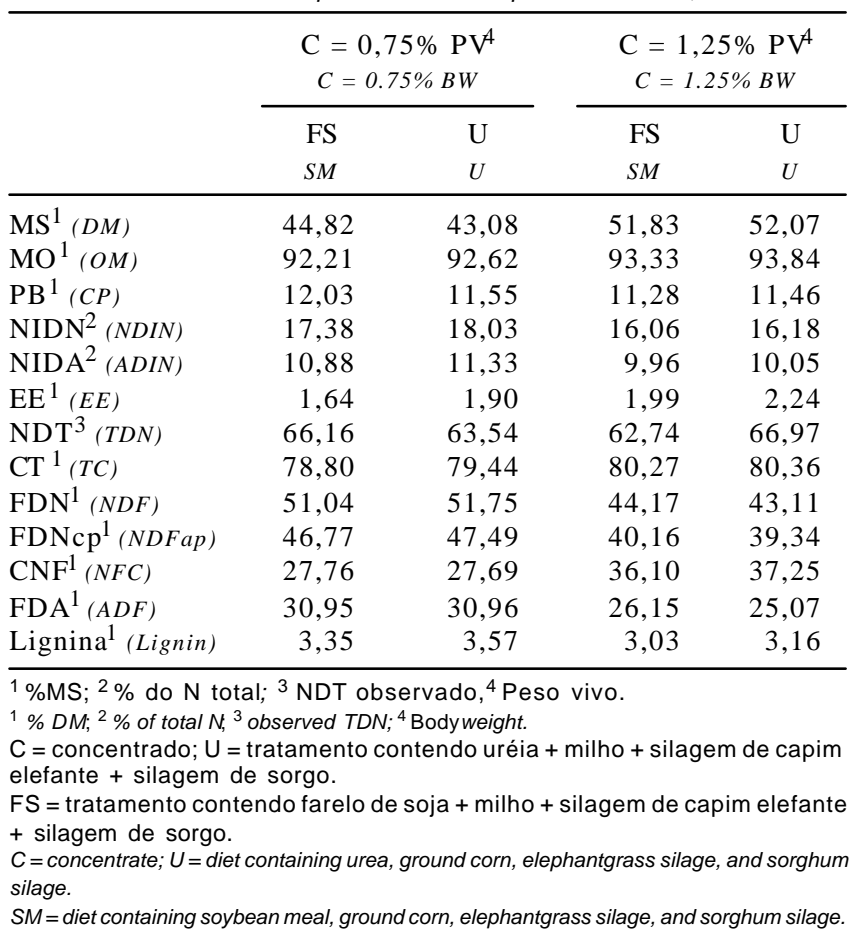

Também foram realizadas as análises de compostos nitrogenados e de derivados de purinas (alantoína e ácido úrico) na urina, pelo método colorimétrico, conforme técnica de Fujihara et al. (1987), descrita por Chen \& Gomes (1992).

As purinas microbianas absorvidas ( $\mathrm{X}, \mathrm{mmol} / \mathrm{dia}$ ) foram calculadas por meio da excreção de derivados de purinas na urina $(\mathrm{Y}, \mathrm{mmol} / \mathrm{dia})$, por meio da equação: $\mathrm{Y}=$ $0,85 \mathrm{X}+0,385 \mathrm{PV} 0,75$, em que 0,85 é a recuperação de purinas absorvidas como derivados urinários de purinas e 0,385 $\mathrm{PV}^{0,75}$, a contribuição endógena para a excreção de purinas (Verbic et al., 1990).

A partir da excreção média diária de creatinina obtida por Valadares et al. (1997c) de 24,04 mg/kg PV/dia, e da concentração de creatinina $(\mathrm{mg} / \mathrm{L})$ na amostra spot de urina, foi estimado o volume diário de urina utilizando-se a equação:

PV (kg) x excreção de creatinina $(\mathrm{mg} / \mathrm{kg} \mathrm{PV})$

Volume de urina $(\mathrm{L})=$

Concentração de creatinina (mg/L)

Esse volume foi utilizado para calcular as excreções estimadas diárias de bases purinas de cada animal.

Ao final do experimento, foram abatidos 14 animais. $\mathrm{O}$ trato gastrintestinal foi esvaziado e lavado e, depois de escorrer a água, foi pesado em conjunto com cabeça, couro, pés, cauda, sangue, rúmen, retículo, omaso, abomaso, intestino delgado, intestino grosso, gordura interna (mesentério + gorduras perirenal e pericardíaca), coração, rins, fígado, baço e pulmões, para obtenção do peso do corpo vazio final.

As carcaças foram divididas em duas meias-carcaças e, seqüencialmente, foram pesadas e resfriadas em câmara fria a $-5^{\circ} \mathrm{C}$ durante 18 horas para avaliação dos rendimentos dos cortes básicos: acém, paleta, ponta-de-agulha, coxão e alcatra completa. Os rendimentos dos cortes básicos foram determinados em relação ao peso da carcaça, sendo o dianteiro separado do traseiro na posição entre a $5 \underline{a}$ e a $6 \underline{a}$ costelas. O dianteiro compreendeu o acém e a paleta completa e o traseiro incluiu ponta-de-agulha, coxão e alcatra completa. Na carcaça esquerda, foi medida a área transversal do músculoLongissimus dorsi (área de olho-de-lombo), à altura da 12a costela. Amostras da seção da 92 à 11 a costelas (seção HH) foram retiradas para dissecação e predição das porcentagens de músculo, osso e tecido adiposo segundo equações preconizadas por Hankins \& Howe (1946): proporção de músculo: $Y=16,08+0,80 X$; proporção de tecido adiposo: $\mathrm{Y}=3,54+0,80 \mathrm{X}$; proporção de ossos: $\mathrm{Y}=5,52+0,57 \mathrm{X}$, em que $\mathrm{X}=$ porcentagem dos componentes na seção HH.

\section{Resultados e Discussão}

Constam na Tabela 3 os consumos médios e as digestibilidades dos nutrientes, seus respectivos coeficientes de variação e suas interações, obtidos nos diferentes tratamentos.

Os consumos de MS e de MO foram afetados pelos níveis de concentrado ( $\mathrm{P}<0,05$ e $\mathrm{P}<0,01$, respectivamente), sendo maiores nos animais que ingeriram $1,25 \%$ do PV.

Não houve interação $(P>0,05)$ fontes de proteína $\times$ níveis de concentrado. O consumo de CNF foi mais alto $(\mathrm{P}<0,05)$ quando o nível de concentrado foi maior. Todavia, na avaliação do efeito da fonte protéica, não houve diferença na ingestão de MS, observando-se consumos de 8,13 e $8,21 \mathrm{~kg} \mathrm{MS} /$ dia, respectivamente, para os animais recebendo uréia ou farelo de soja. O mesmo foi relatado por Obeid et al. (1980) e Magalhães (2003), que não notaram diferença no consumo quando a deficiência de proteína das rações foi suprida exclusivamente pela uréia. Entretanto, Feijó et al. (1997) e Silva et al. (1999), ao fornecerem rações nas quais o farelo de soja foi gradativamente substituído pela uréia $(0$, 50 e $100 \%$ ) no concentrado, observaram comportamento decrescente no consumo à medida que a uréia substituiu a 
Tabela 3 - Médias, coeficiente de variação (CV) e significância obtidos para o consumo médio e a digestibilidade dos nutrientes de dietas formuladas com dois níveis de uréia e concentrado

Table 3 - Means, coefficient of variation (CV) and P-values observed for intake and apparent total tract digestibility of nutrients in steers fed diets with different levels of urea and concentrate

\begin{tabular}{|c|c|c|c|c|c|c|c|c|}
\hline & \multicolumn{2}{|c|}{$\begin{array}{l}\text { Uréia } \\
\text { Urea }\end{array}$} & \multicolumn{2}{|c|}{$\begin{array}{c}\text { Concentrado }(\% \mathrm{PV}) \\
\text { Concentrate }(\% B W)\end{array}$} & \multirow[t]{2}{*}{ CV (\%) } & \multicolumn{3}{|c|}{$\begin{array}{l}\text { Significância } \\
\text { Significant }\end{array}$} \\
\hline & $\begin{array}{l}\text { Com } \\
\text { With }\end{array}$ & $\begin{array}{c}\text { Sem } \\
\text { Without }\end{array}$ & 0,75 & 1,25 & & $\mathrm{U}$ & $\mathrm{C}$ & $\mathrm{U} \times \mathrm{C}$ \\
\hline \multicolumn{9}{|c|}{$\begin{array}{l}\text { Consumo }(\mathrm{kg} / \mathrm{dia}) \\
\text { Intake }(\mathrm{kg} / \text { day })\end{array}$} \\
\hline $\mathrm{PB}(C P)$ & 1,04 & 1,09 & 1,00 & 1,09 & 8,21 & ns & $\mathrm{ns}$ & ns \\
\hline $\mathrm{EE}(E E)$ & 0,18 & 0,16 & 0,14 & 0,19 & 9,45 & $*$ & $* *$ & $\mathrm{~ns}$ \\
\hline $\mathrm{FDN}(N D F)$ & 3,91 & 3,92 & 3,99 & 3,88 & 12,03 & ns & $\mathrm{ns}$ & ns \\
\hline $\mathrm{CNF}(N F C)$ & 2,75 & 2,48 & 2,02 & 3,21 & 9,34 & ns & $*$ & ns \\
\hline $\operatorname{NDT}(T D N)$ & 5,39 & 5,24 & 4,74 & 5,90 & 9,32 & ns & $* *$ & $\mathrm{~ns}$ \\
\hline \multicolumn{9}{|c|}{$\begin{array}{c}\text { Consumo }(\% \mathrm{PV}) \\
\text { Intake }(\% B W)\end{array}$} \\
\hline \multicolumn{9}{|c|}{$\begin{array}{c}\text { Digestibilidade (\%) } \\
\text { Digestibility }(\%)\end{array}$} \\
\hline $\operatorname{MS}(D M)$ & 63,68 & 64,96 & 62,18 & 66,46 & 4,35 & $\mathrm{~ns}$ & $* *$ & ns \\
\hline $\mathrm{MO}(O M)$ & 65,21 & 66,65 & 64,20 & 67,67 & 4,59 & ns & $*$ & $\mathrm{~ns}$ \\
\hline $\mathrm{PB}(C P)$ & 74,61 & 74,23 & 75,46 & 73,37 & 4,28 & ns & $\mathrm{ns}$ & ns \\
\hline $\mathrm{EE}(E E)$ & 78,83 & 66,29 & 67,06 & 78,06 & 6,91 & - & - & $* *$ \\
\hline $\mathrm{FDN}(N D F)$ & 47,48 & 49,12 & 49,83 & 46,77 & 9,03 & $\mathrm{~ns}$ & $\mathrm{~ns}$ & $\mathrm{~ns}$ \\
\hline $\mathrm{CNF}(N F C)$ & 90,39 & 92,40 & 89,88 & 92,91 & 6,02 & $\mathrm{~ns}$ & $\mathrm{~ns}$ & ns \\
\hline $\operatorname{NDT}(T D N)$ & 66,16 & 63,54 & 62,74 & 66,97 & 5,13 & $\mathrm{~ns}$ & $*$ & ns \\
\hline
\end{tabular}

* e ** Significativo $(P<0,05)$ e $(P<0,01)$, respectivamente, pelo teste $F$. ns: não-significativo.

* and ${ }^{* *}$ Significant at $(P<0.05)$ and $(P<0.01)$, respectively, by $F$ test. ns: not significant.

soja. Esses autores atribuíram esse comportamento ao sabor amargo da uréia e, conseqüentemente, à sua baixa palatabilidade.

Os consumos de FDN, tanto em $\mathrm{kg} / \mathrm{dia}$ quanto em $\%$ do $\mathrm{PV}$, não foram influenciados $(\mathrm{P}>0,05)$ pelos níveis de concentrado ou pela fonte de proteína. As dietas com maior nível de concentrado continham menores teores de FDN, mas resultaram em mais altos consumos de MS, o que provavelmente explica a ausência de efeito do nível de concentrado. Os consumos de FDN (\%PV) variaram de 1,20 a 1,3\% do PV. Magalhães et al. (2003) também não notaram diferença no consumo de FDN (em média 1,08\% PV) quando forneceram dietas com níveis crescentes de uréia $(0 ; 0,65$; 1,30 e 1,95\% da MS total). O consumo diário de NDT também aumentou $(\mathrm{P}<0,01)$ com os níveis de concentrado, sendo obtidas médias de 4,74 e 5,90 (kg/dia), respectivamente, para os animais que receberam concentrado nas proporções de 0,75 e $1,25 \%$ PV.

A fonte protéica não afetou o consumo de nenhum dos nutrientes avaliados, à exceção do $\mathrm{EE}(\mathrm{P}<0,05)$, que sofreu efeito, também, dos níveis de concentrado $(\mathrm{P}<0,01)$. Entre os ingredientes das dietas, o milho contém a maior porcentagem de EE (4\%), o que justifica o maior consumo deste nutriente no tratamento com uréia (dieta formulada com maior proporção de milho) e naquele com maior participação de concentrado $(\mathrm{P}<0,01)$.

O desempenho animal é determinado por vários fatores, especialmente o consumo de MS, que determina o nível de ingestão de nutrientes. Segundo Haddad (1984), o uso de níveis mais elevados de NNP na dieta, como o de uréia acima do limite de $1 \%$ na MS total, poderia prejudicar a palatabilidade e, conseqüentemente, provocar redução do consumo. Wilson et al. (1975), no entanto, avaliando o efeito de níveis crescentes de uréia $(1,0 ; 1,65 ; 2,30 ;$ e 3,0\% na MS) em rações, forneceram uréia via oral ou diretamente no rúmen e notaram que a uréia parece diminuir o consumo quando incluída na dieta em níveis superiores a $2 \%$. Neste estudo, os teores mínimos e máximos de uréia na ração foram de aproximadamente 1,34 e 2,26\% da MS total, respectivamente. Não houve efeito da interação fontes de proteína $\times$ 
níveis de concentrado sobre os coeficientes de digestibilidade de MS, MO, PB, FDN, CNF e NDT. As digestibilidades da MS $(62,18$ x 66,46) e MO $(64,20$ x 67,67) aumentaram com a maior oferta de concentrado.

O tratamento com maior nível de concentrado ocasionou aumento no teor de CNF (elevada digestibilidade) da dieta, justificando as maiores digestibilidades obtidas para MS e MO e, consequientemente, o maior teor de NDT $(62,74$ x 66,97\%).

As digestibilidades de $\mathrm{PB}$ e CNF não foram influenciadas ( $\mathrm{P}>0,05)$ pelas fontes protéicas ou pelos níveis de concentrado. Houve interação $(\mathrm{P}<0,01)$ fonte protéica $\times$ nível de concentrado para a digestibilidade do EE (Tabela 4).

No nível de concentrado correspondente a $0,75 \%$ do PV, a substituição do farelo de soja pela uréia aumentou $(\mathrm{P}<0,01)$ a digestibilidade do EE, que não foi alterada $(\mathrm{P}>0,05)$ pela inclusão de uréia no nível de $1,25 \% \mathrm{PV}$ de concentrado. $\mathrm{Na}$ ausência de uréia, a digestibilidade do EE foi maior ( $\mathrm{P}<0,01)$ no nível de $1,25 \% \mathrm{PV}$ de concentrado, mas, na presença de uréia, não foi influenciada $(\mathrm{P}>0,05)$ pelo nível de concentrado.

Na Tabela 5 são apresentados as médias, os coeficientes de variação e as probabilidades para o peso vivo inicial (PVI), o peso vivo final (PVF), o peso de corpo vazio final (PCVZ), o ganho de peso (GP), a relação peso de corpo vazio/peso vivo (PCVZ/PV) e as proporções de músculo $(\mathrm{M})$, gordura $(\mathrm{G})$ e ossos $(\mathrm{O})$ na carcaça. Não houve efeito da interação $(\mathrm{P}>0,05)$ nível de concentrado $\times$ fonte de proteína sobre nenhuma dessas variáveis.

A adição de uréia e o aumento do nível de concentrado não afetaram os parâmetros avaliados $(\mathrm{P}<0,01)$, exceto o ganho de peso, que foi maior $(\mathrm{P}<0,05)$ nos animais que receberam $1,25 \%$ do $\mathrm{PV}(1,34 \mathrm{~kg} / \mathrm{dia})$. A diferença de mais de $0,3 \mathrm{~kg} /$ dia está relacionada ao maior consumo de MS e de energia pelos animais que receberam mais concentrado. A ausência de diferença estatística para o ganho de peso em

Tabela 4 - Coeficientes de digestibilidade do EE em novilhos alimentados com dietas formuladas com diferentes níveis de concentrado e uréia

Table 4 - Coefficients of digestibility of EE in steers fed diets with different levels of urea and concentrate

\begin{tabular}{lcc}
\hline \multirow{2}{*}{$\begin{array}{l}\text { Nível de concentrado } \\
\text { Concentrate level }\end{array}$} & \multicolumn{3}{c}{ Nível de uréia } \\
& $0 \%$ & $100 \%$ \\
\cline { 2 - 3 } & $52,86 \mathrm{Bb}$ & $81,26 \mathrm{Aa}$ \\
$0,75 \% \mathrm{PV}$ & $79,73 \mathrm{Aa}$ & $76,40 \mathrm{Aa}$ \\
\hline $1,25 \% \mathrm{PV}$ & & \multicolumn{2}{c}{} \\
\hline
\end{tabular}

Letras maiúsculas comparam médias nas colunas e minúsculas nas linhas pelo teste Tukey $(\mathrm{P}<0,05)$

Capital letters compare means in column and small letters compare means in the row by Tukey test $(P<0.05)$ relação à fonte protéica pode ter sido ocasionada pelo número pequeno de animais utilizados no estudo. Obeid et al. (1980), substituindo a proteína de soja pelo NNP da uréia $(0,50$ e $100 \%)$ na dieta de 72 novilhos Nelores inteiros, observaram que a inclusão de $100 \%$ de uréia comprometeu o ganho de peso dos animais $(1,03 ; 1,02$ e $0,80 \mathrm{~kg} / \mathrm{dia}) \mathrm{e}$ reduziu o consumo de proteína $(0,73 ; 0,92$ e $0,98 \mathrm{~kg}$, respectivamente, para 0,50 e $100 \%$ de substituição da proteína da soja pela uréia), possível causa do menor desempenhos dos animais. Feijó et al. (1997), trabalhando com os mesmos níveis de substituição na dieta de 72 bovinos F1 Pardo Suíço x Nelore não-castrados (412 kg de PV inicial) mantidos em confinamento durante 92 dias, também verificaram menor ganho de peso nos animais dos tratamentos com substituição totalda proteína do farelo de soja pela uréia (1,71; 1,57 e 1,24 kg/dia). Coutinho Filho et al. (1995) também notaram menores ganhos em 40 animais anelorados confinados durante 84 dias alimentados com rações contendo duas fontes de nitrogênio (farelo de algodão e milho ou uréia e milho), sendo observados ganhos de 0,60 e $0,70 \mathrm{~kg} /$ dia, respectivamente. Fernandes et al. (2004) avaliaram a influência do aumento da proteína metabolizável, por meio da inclusão de farelo de soja em substituição à uréia, no desempenho de 24 animais Nelores e 13 Canchim e verificaram menor ganho de peso diárionaqueles que receberam maior proporção de uréia na dieta $(1,14 ; 1,26$ e 1,28 kg/dia, respectivamente, para 2,1 e $0 \%$ de uréia na MS total das rações).

Quanto à composição tecidual, a porcentagem de osso (O) foi maior $(\mathrm{P}<0,05)$ nos animais que receberam concentrado na proporção de $0,75 \% \mathrm{PV}$.

As médias e os coeficientes de variação para os rendimentos de carcaça quente (RCQ) e de carcaça fria (RCF), a área de olho-de-lombo (AOL) e os rendimentos de alcatra (ALC), coxão (COX), ponta-de-agulha (POTAGL), paleta (PAL) e acém (ACEM), além dos totais de dianteiro (DINT) e traseiro (TRAS), são apresentados na Tabela 6 .

Não houve efeito da fonte protéica nem dos níveis de concentrado sobre o rendimento de carcaça quente (RCQ), que foi, em média, de $50,05 \%$, próximo aos valores citados na literatura para bovinos mestiços leiteiros (Leme et al., 2000; Detmann, 2002; Moraes, 2003). Souza et al. (2002) não everificaram diferenças no rendimento de carcaça $(48,7 \%$, em média) de novilhos mestiços em confinamento alimentados com dietas formuladas com níveis crescentes de uréia $(0 ; 0,5 ; 1,0$ e $1,5 \%)$. O mesmo foi observado por Magalhães et al. (2003), que não encontraram diferença no rendimento de carcaça $(52,10 \%)$ de animais alimentados com dietas contendo níveis crescentes de uréia $(0 ; 0,65 ; 1,30$ e 1,95\%). 
Tabela 5 - Médias, coeficiente de variação (CV) e significância para os pesos vivos inicial (PVI) e final (PVF), o peso de corpo vazio final (PCVF), o ganho de peso (GP), a relação PCVF/PV e as proporções de músculo (M), osso (O) e gordura (G) obtidos com as dietas contendo dois níveis de uréia $(U)$ e concentrado $(C)$

Table 5 - Means, coefficient of variation (CV) and P-values observed for the initial body weight (IBW) and final body weight (FBW), empty body weight $(E B W)$, average daily gain of body weight (ADG), EBW/BW ratio and proportion of the muscle $(M)$, bone $(B)$ and fat $(F)$

\begin{tabular}{|c|c|c|c|c|c|c|c|c|}
\hline & \multicolumn{2}{|c|}{$\begin{array}{l}\text { Uréia } \\
\text { Urea }\end{array}$} & \multicolumn{2}{|c|}{$\begin{array}{c}\text { Concentrado }(\% \mathrm{PV}) \\
\text { Concentrate }(\% B W)\end{array}$} & \multirow[t]{2}{*}{$\mathrm{CV}(\%)$} & \multicolumn{3}{|c|}{$\begin{array}{l}\text { Significância } \\
\text { Significant }\end{array}$} \\
\hline & $\begin{array}{l}\text { Com } \\
\text { With }\end{array}$ & $\begin{array}{c}\text { Sem } \\
\text { Without }\end{array}$ & 0,75 & 1,25 & & $\mathrm{U}$ & $\mathrm{C}$ & $\mathrm{U} \times \mathrm{C}$ \\
\hline PVI $(\mathrm{kg})(I B W, k g)$ & 284,50 & 287,44 & 284,31 & 287,62 & 10,64 & ns & ns & $\mathrm{ns}$ \\
\hline $\operatorname{PVF}(\mathrm{kg})(F B W, k g)$ & 355,56 & 364,86 & 348,13 & 372,31 & 8,83 & $\mathrm{~ns}$ & ns & $\mathrm{ns}$ \\
\hline $\operatorname{PVCZ}(\mathrm{kg})(E B W, k g)$ & 300,30 & 308,64 & 290,79 & 318,15 & 11,27 & ns & ns & $\mathrm{ns}$ \\
\hline GMP (kg/dia) (ADG, $k g / d a y)$ & 1,14 & 1,23 & 1,01 & 1,34 & 9,50 & $\mathrm{~ns}$ & $* *$ & $\mathrm{~ns}$ \\
\hline $\mathrm{PCVZ/PV}(E B W / B W)$ & 84,34 & 83,71 & 82,73 & 85,33 & 5,15 & $\mathrm{~ns}$ & ns & $\mathrm{ns}$ \\
\hline Músculo (\%) (Muscle, \%) & 56,94 & 57,14 & 55,21 & 58,87 & 5,52 & $\mathrm{~ns}$ & $\mathrm{~ns}$ & $\mathrm{~ns}$ \\
\hline Osso (\%) (Bone, \%) & 18,81 & 19,72 & 20,58 & 18,95 & 8,73 & $\mathrm{~ns}$ & $*$ & $\mathrm{~ns}$ \\
\hline Gordura $(\%)($ Fat, $\%)$ & 24,02 & 22,55 & 23,27 & 23,31 & 11,84 & ns & $\mathrm{ns}$ & $\mathrm{ns}$ \\
\hline
\end{tabular}

* $e^{* *}$ Significativo $(P<0,05)$ e $(P<0,01)$, respectivamente, pelo teste $F$. ns - não-significativo.

${ }^{*}$ and ${ }^{* *}$ Significant at $(P<0.05)$ and $(P<0.01)$, respectively, by $F$ test. ns - not significant

Tabela 6 - Médias, coeficiente de variação (CV) e significância obtidos para o rendimentos de carcaça quente (RCQ), de carcaça fria (RCF), de área de olho-de-lombo (AOL) e dos cortes comerciais obtidos com as dietas contendo dois níveis de uréia (U) e concentrado $(\mathrm{C})$

Table 6 - Means, coefficient of variation (CV) and P-values observed for the yields of hot carcass (HCY), cold carcass yield (CCY), rib eye area (REA), and commercial cuts in steers fed diets with different levels of urea (U) and concentrate (C)

\begin{tabular}{|c|c|c|c|c|c|c|c|c|}
\hline & \multicolumn{2}{|c|}{$\begin{array}{l}\text { Uréia } \\
\text { Urea }\end{array}$} & \multicolumn{2}{|c|}{$\begin{array}{c}\text { Concentrado }(\% \mathrm{PV}) \\
\text { Concentrate }(\% B W)\end{array}$} & \multirow[t]{2}{*}{$\mathrm{CV}(\%)$} & \multicolumn{3}{|c|}{$\begin{array}{l}\text { Significância } \\
\text { Significant }\end{array}$} \\
\hline & $\begin{array}{l}\text { Com } \\
\text { With }\end{array}$ & $\begin{array}{c}\text { Sem } \\
\text { Without }\end{array}$ & 0,75 & 1,25 & & $\mathrm{U}$ & $\mathrm{C}$ & $\mathrm{U} \times \mathrm{C}$ \\
\hline \multicolumn{9}{|c|}{$\begin{array}{l}\text { Característica de carcaça } \\
\text { Carcass characteristic }\end{array}$} \\
\hline \multicolumn{9}{|c|}{$\begin{array}{l}\text { Rendimento dos cortes básicos (\%) } \\
\text { Cut trade yield }\end{array}$} \\
\hline Traseiro especial (Hindquarter) & 48,03 & 48,96 & 48,40 & 48,60 & 2,56 & $\mathrm{~ns}$ & $\mathrm{~ns}$ & $\mathrm{~ns}$ \\
\hline Dianteiro (Forequarter) & 39,74 & 39,12 & 39,22 & 39,63 & 3,63 & $\mathrm{~ns}$ & $\mathrm{~ns}$ & ns \\
\hline Coxão (Beef round) & 29,64 & 30,50 & 30,32 & 29,70 & 5,51 & ns & $\mathrm{ns}$ & ns \\
\hline
\end{tabular}

* $e^{* *}$ Significativo $(P<0,05)$ e $(P<0,01)$, respectivamente, pelo teste $F$. ns - não-significativo.

${ }^{*}$ and ${ }^{* *}$ Significant at $(P<0.05)$ and $(P<0.01)$, respectively, by $F$ test. $n s-$ not significant

No entanto, Feijó et al. (1997) observaram menor rendimento de carcaça $(52,9 \%)$ quando substituíram $100 \%$ do farelo de soja por uréia na dieta de novilhos F1 Pardo-Suíço x Nelore.

Nenhum efeito do nível de concentrado ou da adição de uréia foi verificado nos demais cortes d e carcaça estudados, exceto a alcatra. Segundo Luchiari Filho (2000), é desejável que uma carcaça apresente em torno de 45 a $50 \%$ de traseiro especial, 38 a $43 \%$ de dianteiro com cinco costelas e 12 a $16 \%$ de ponta-de-agulha. Os resultados deste trabalho estão de acordo com esses valores. Rocha et al. (1999) e Leme et al. (2000) também avaliaram o rendimento dos cortes básicos de novilhos Holandês e concluíram que esses animais apresentam bom potencial para produção de carne em confinamento. Entretanto, verifica-se escassez de dados na literatura obtidos em estudos sobre o rendimento dos cortes comerciais em bovinos mestiços leiteiros. 
Tabela 7 - Efeito dos níveis de uréia e de concentrado sobre a área de olho-de-lombo e o rendimento da paleta

Table 7- Effect of urea and concentrate levels on rib eye area and shoulder clod yield

Área de olho-de-lombo

Rib eye are

\begin{tabular}{|c|c|c|}
\hline \multirow[t]{2}{*}{$\begin{array}{l}\text { Nível de concentrado } \\
\text { Concentrate level }\end{array}$} & \multicolumn{2}{|c|}{$\begin{array}{l}\text { Nível de uréia } \\
\text { Urea level }\end{array}$} \\
\hline & $0 \%$ & $100 \%$ \\
\hline $0,75 \% \mathrm{PV}$ & $49,00 \mathrm{Bb}$ & $62,92 \mathrm{Aa}$ \\
\hline $1,25 \% \mathrm{PV}$ & 63,99Aa & $55,52 \mathrm{Aa}$ \\
\hline
\end{tabular}

$0,75 \% \mathrm{PV}$

$18,97 \mathrm{Aa}$

$17,97 \mathrm{Ab}$

$1,25 \% \mathrm{PV}$

$17,72 \mathrm{Ba}$

$18,46 \mathrm{Aa}$

Letras maiúsculas comparam médias nas colunas e minúsculas nas linhas $(\mathrm{P}<0,05)$ pelo teste Tukey.

Capital letters compare means in column and small letters compare means in the row $(P<0.05)$ by Tukey test.

Verificou-se efeito dos níveis de concentrado sobre o rendimento de alcatra $(\mathrm{P}<0,05)$, de modo que maior a porcentagem de alcatra $(18,85 \%)$ foi obtida nas carcaças dos animais que receberam concentrado na proporção de $1,25 \%$ do PV, possivelmente em razão do maior ganho de peso desses animais. Segundo Berg \& Butterfield (1979), independentemente da raça, o animal tende a manter, dentro de certos limites, um equilíbrio entre os quartos traseiro e dianteiro e, conseqüentemente, entre os cortes.

Oliveira (1998), avaliando o efeito de níveis de concentrado sobre os cortes básicos da carcaça de bovinos Nelore na fase de engorda, observou respostas quadrática e linear, respectivamente, para rendimentos de acém e ponta-deagulha e de alcatra. Entretanto, Ferreira et al. (2000) e Gesualdi Jr. et al. (2000) forneceram diferentes níveis de concentrado na dieta de animais F1 Europeu x Zebu e não encontraram efeitos significativos sobre os cortes básicos da carcaça. O mesmo foi observado por Silva et al. (2002) em experimentos nos quais forneceram diferentes níveis de concentrado nas rações de 36 bovinos.

Houve interação $(\mathrm{P}<0,05)$ nível de concentrado $\times$ fonte protéica para a área de olho-de-lombo (AOL) e o rendimento de paleta (Tabela 7 ).

Considerando o nível de $0,75 \%$ de concentrado, observou-se que a AOL foi aumentada $(\mathrm{P}<0,05)$ pela inclusão de uréia $(49,00 \times 62,92)$, possivelmentecomo conseqüência do aumento da energia da dieta, enquanto, no nível de $1,25 \%$ PV de oferta de concentrado, a AOL não foi influenciada $(63,99$ x 55,52) pela inclusão de uréia. Quando fornecida uréia na dieta, a AOL não foi afetada $(\mathrm{P}>0,05)$ pelos níveis de concentrado $(66,92$ x 55,52), mas, na ausência de uréia, o nível de concentrado de $1,25 \%$ do PV resultou em maior $(\mathrm{P}<0,05)$ AOL $(49,00 \times 63,99)$.

$\mathrm{O}$ rendimento de paleta foi reduzido $(\mathrm{P}<0,05)$ pela inclusão de uréia $(18,97$ x 17,97) no nível de $0,75 \%$ de concentrado, mas, no nível de $1,25 \%$ de concentrado, não foi influenciado $(\mathrm{P}>0,05)$ pela inclusão de uréia na dieta $(17,72$ x 18,46). Considerando apenas os níveis de uréia, verificou-se que, na ausência de uréia, o rendimento de paleta foi mais baixo $(\mathrm{P}<0,05)$ no menor nível de concentrado $(18,97 \times 17,72)$, enquanto, na presença de uréia, o rendimento desse corte não foi influenciado pelos níveis de concentrado $(17,47 \times 18,46)$.

Na Tabela 8 são apresentados as médias, os coeficientes de variação e as interações $\mathrm{N}$-uréia plasmática $\times$ excreção diária de uréia $\times$ eficiência de síntese microbiana.

A eficiência de síntese microbiana não foi afetada pela fonte protéica nem pelos níveis de concentrado e apresentou média de 112,55 g de PB por kg de NDT, valor levemente inferior ao citado pelo NRC (2001), de $130 \mathrm{~g} \mathrm{~PB} \mathrm{mic/kg} \mathrm{de}$ NDT, e semelhante ao encontrado por Rennó (2003), de $110 \mathrm{~g} \mathrm{~PB} \mathrm{mic/kg} \mathrm{de} \mathrm{NDT.}$

A concentração de N-uréia no plasma não foi influenciada $(\mathrm{P}>0,05)$ pela fonte protéica, mas foi reduzida $(\mathrm{P}<0,05)$ pelos níveis de concentrado. Com o aumento do nível de concentrado, possivelmente a disponibilidade de energia ruminal aumentou, resultando em redução na concentração de amônia ruminal e, conseqüentemente, de uréia no plasma. Nota-se também que, numericamente, a substituição do farelo de soja pela uréia aumentou o NUP de 13,46 para $15,43 \mathrm{mg} / \mathrm{dL}$.

A excreção de uréia na urina, tanto em $\mathrm{mg} / \mathrm{kg} \mathrm{PV}$ quanto em g/dia, apresentou comportamento numérico semelhante ao de NUP, contudo, ambas as diferenças foram significativas. Houve redução na excreção de uréia $(\mathrm{P}<0,05)$ com o aumento do nível de concentrado, provavelmente em virtude da maior disponibilidade de energia ruminal com a menor concentração de amônia ruminal. A substituição do farelo de soja pela uréia também resultou em aumento $(\mathrm{P}<0,01)$ na excreção urinária de uréia.

Oliveira et al. (2001) alimentaram vacas leiteiras com dietas contendo níveis crescentes de uréia $(0 ; 0,7 ; 1,4$; $2,1 \%$ na base da MS) e notaram aumento linear nos valores de NUP e na excreção de uréia, resultados atribuídos à redução na eficiência de utilização de amônia no rúmen. Da mesma forma, Cecava \& Hancock (1994) verificaram que a excreção de $\mathrm{N}$ nos animais alimentados com dietas contendo uréia ( $1,35 \%$ na MS) foi maior que naqueles que receberam dietas formuladas com combinações de farelo de soja e farinha de penas. 
Tabela 8 - Médias, coeficiente de variação e significância obtidos para N-uréia plasmática (NUP), excreções diárias de uréia (EU) e eficiência de síntese microbiana (g PBmic/kg NDT) para as dietas contendo dois níveis de uréia (U) e concentrado (C)

Table 8 - Means, coefficient of variation (CV) and P-values observed for plasma urea-N (PUN), daily urinary excretion of urea (UE) and microbial efficiency ( $g$ mic - CP/kg TDN) in steers fed diets with different levels of urea $(U)$ and concentrate $(C)$

\begin{tabular}{|c|c|c|c|c|c|c|c|c|}
\hline & \multicolumn{2}{|c|}{$\begin{array}{l}\text { Uréia } \\
\text { Urea }\end{array}$} & \multicolumn{2}{|c|}{$\begin{array}{c}\text { Concentrado }(\% \mathrm{PV}) \\
\text { Concentrate }(\% B W)\end{array}$} & \multirow[t]{2}{*}{$\mathrm{CV}(\%)$} & \multicolumn{3}{|c|}{$\begin{array}{l}\text { Significância } \\
\text { Significant }\end{array}$} \\
\hline & $\begin{array}{l}\text { Com } \\
\text { With }\end{array}$ & $\begin{array}{c}\text { Sem } \\
\text { Without }\end{array}$ & 0,75 & 1,25 & & $\mathrm{U}$ & $\mathrm{C}$ & $\mathrm{U} \times \mathrm{C}$ \\
\hline NUP (mg/dL) (PUN) & 15,43 & 13,46 & 16,60 & 12,46 & 21,87 & $\mathrm{~ns}$ & $*$ & $\mathrm{~ns}$ \\
\hline $\mathrm{EU}(\mathrm{mg} / \mathrm{kgPV})(U E, m g / k g B W)$ & 393,60 & 328,73 & 417,32 & 305,01 & 15,21 & $*$ & $* *$ & $\mathrm{~ns}$ \\
\hline $\mathrm{EU}(\mathrm{g} / \mathrm{dia})(U E, \mathrm{~g} /$ day $)$ & 139,08 & 117,69 & 143,22 & 113,69 & 18,36 & $*$ & ns & $\mathrm{ns}$ \\
\hline g PB mic/kg NDT ( $g C P m i c / k g T D N)$ & 107,65 & 117,45 & 114,51 & 110,59 & 15,58 & ns & ns & ns \\
\hline
\end{tabular}

${ }^{*} \mathrm{e}^{* *}$ Significativo $(\mathrm{P}<0,05)$ e $(\mathrm{P}<0,01)$, respectivamente, pelo teste $\mathrm{F}$. ns - não-significativo.

* and ${ }^{* *}$ Significant at $(P<0.05)$ and $(P<0.01)$, respectively, by $F$ test. ns - not significant.

Rennó (2003) observou aumento linear de 350,5 mg/kg PV na concentração de NUP e nas excreções médias de uréia ao fornecer diferentes níveis de uréia $(0 ; 0,65 ; 1,30$ e 1,95\% na MS) na dieta de novilhos. Magalhães (2003), por sua vez, utilizando níveis de uréia semelhantes aos descritos anteriormente, em novilhos mestiços, não encontrou diferença quanto a NUP e EU, sendo obtidas médias de $14,92 \mathrm{mg} / \mathrm{dL}$ e $458,95 \mathrm{mg} / \mathrm{kg} \mathrm{PV}$, respectivamente.

\section{Conclusões}

Aumentos na oferta de concentrado resultam em maior consumo de energia e em maior ganho de peso.

A substituição de farelo de soja por uréia não altera o ganho de peso de bovinos com potencial genético para ganhos de 1,1 a $1,2 \mathrm{~kg} /$ dia.

\section{Literatura Citada}

BERG, R.T.; BUTTERFIELD, R.M. Nuevos conceptos sobre desarrollo de ganado vacuno. In: El crecimiento del ganado vacuno y la producción de carne de vacuno. Zaragoza: Acribia, 1979. p.16-29.

CECAVA, M.J.; HANCOCK, D.L. Effects of anabolic steroids on nitrogen metabolism and growth of steers fed corn silage and corn-based diets supplemented with urea or combinations of soybean meal and feather meal. Journal of Animal Science, v.72, p.515-522, 1994.

CHEN, X.B.; GOMES, M.J. Estimation of microbial protein supply to sheep and cattle based on urinary excretion of purine derivatives - an overview of technical details. Bucksburnd, Aberdeen: Rowett Research Institute; International Feed Resources Unit, 1992. 21p. (Occasional publication).

COELHO DA SILVA, J.F.; LEÃO, M.I. Fundamentos de nutrição de ruminantes. Piracicaba: Livroceres, 1979. 380p.

COUTINHO FILHO, J.L.V.; SAMPAIO, A.A.M., EZEQUIEL, J.M.B. et al. Efeito de fontes de nitrogênio e da cobertura de cocho sobre o desempenho de bovinos confinados. Revista Sociedade Brasileira de Zootecnia, v.24, n.3, p.363-370, 1995.

CRAIG, W.M.; HONG, B.J.; BRODERICK, G.A. et al. In vitro inoculum enriched with particle associated microorganisms for determining rates of fiber digestion and protein degradation. Journal of Dairy Science, v.50, n.4, p.523-526, 1984.

DETMANN, E. Níveis de proteína bruta em suplementos múltiplos para terminação de bovinos em pastejo: desempenho produtivo, simulação e validação de parâmetros da cinética digestiva. Viçosa, MG: Universidade de Federal de Viçosa, 2002. 83p. Tese (Doutorado em Zootecnia) - Universidade de Federal de Viçosa, 2002.

FARIA, V.P.; HUBER, J.T. Effect of dietary protein and energy levels on rumen fermentation in Holstein steers. Journal of Animal Science, v.52, n.2, p.452-459, 1984.

FEIJÓ, G.L.D.; SILVA, J.M.; PORTO, J.C.A. et al. Efeito de fontes de nitrogênio e do tipo de silagem no desempenho de bovinos F1 Pardo Suíço x Nelore. In: REUNIÃO ANUAL DA SOCIEDADE BRASILEIRA DE ZOOTECNIA, 34., 1997, Juiz de Fora. Anais... Juiz de Fora: Sociedade Brasileira de Zootecnia, 1997. p. 283-285.

FERNANDES, J.J.R.; PIRES, A.V.; OLIVEIRA JR., R.C. et al. Farelo de soja em substituição à uréia para bovinos de corte em crescimento. In: REUNIÃO ANUAL DA SOCIEDADE BRASILEIRA DE ZOOTECNIA, 41., 2004, Campo Grande Anais... Brasília: Sociedade Brasileira de Zootecnia, 2004. (CD-ROM).

FERREIRA, M.A.; VALADARES FILHO, S.C.; MUNIZ, E.B. et al. Característica das carcaças, biometria do trato gastrointestinal, tamanho dos órgãos internos e conteúdo gastrointestinal de bovinos F1 Simental x Nelore alimentados com dietas contendo vários níveis de concentrado. Revista Brasileira de Zootecnia, v.29, n.4, p.1174-1182, 2000.

FUJIHARA, T.; ORSKOV, E.R.; REEDS, P.J. et al. The effect of protein infusion on urinary excretion of purine derivatives in ruminants nourished by intragastric nutrition. Journal of Agricultural Science, v.109, n.1, p.7-12, 1987.

GESUALDI JR., A.; PAULINO, M.F.; VALADARES FILHO, S.C. et al. Níveis de cooncentrado na dieta de novilhos F1 Limousin $\mathrm{x}$ Nelore: característica de carcaça. Revista Brasileira de Zootecnia, v.20, n.5, p.1467-1473, 2000.

HADDAD, C.M. Uréia em suplementos alimentares. In: SIMPÓSIO SOBRE NUTRIÇÃO DE BOVINOS - Uréia para ruminantes, 2., 1984, Piracicaba. Anais... Piracicaba: Fundação de Estudos Agrários Luiz de Queiroz, 1984. p.119-141.

HALL, M.B. Calculation of non-structural carbohydrate content of feeds that contain non-protein nitrogen. Gainesville: University of Florida, 2000. p.A-25 (Bulletin, 339).

HANKINS, O.G.; HOWE, P.E. Estimation of the composition of beef carcasses and cuts. [T.B.]: United States Department of Agriculture, 1946. p.1-19 (Technical Bulletin - USDA, 926).

HENNESSY, D.W.; KOHUN, P.J.; WILLIAMSON, P.J. et al. The effect of nitrogen and protein supplementation on feed intake, growth and digestive function of steers with different $B o s$ indicus, Bos taurus genotypes when fed a low quality grass 
hay. Australian Journal of Agriculture Research, v.46, p.1121-1136, 1995.

HUNTINGTON, G.B.; ARCHIBEQUE, S.L. Practical aspects of urea and ammonia metabolism in ruminants. In: AMERICAN SOCIETY OF ANIMAL SCIENDE, 1999, Raleigh. Proceedings... Raleigh: American Society of Animal Science, 1999. p.1-11.

LEME, P.R.; BOIN, C.; MARGARIDO, R.C.C. et al. Desempenho em confinamento e característica de carcaça de bovinos machos de diferentes cruzamentos abatidos em três faixas de peso. Revista Brasileira de Zootecnia, v.29, n.6, p.2347-2353, 2000 (supl. 2).

LUCHIARI FILHO, A. Pecuária da carne bovina. 1.ed. São Paulo: Binlife, 2000. 134p.

MAGALHÃES, K.A. Níveis de uréia ou casca de algodão na alimentação da novilhos de origem leiteira em confinamento. Viçosa, MG: Universidade Federal de Viçosa, 2003. 90p. Dissertação (Mestrado em Zootecnia) - Universidade Federal de Viçosa, 2003.

MOORE, J.E.; KUNKÇE, W.E.; ROCHINOTTI, D. et al. Associative effects: are they real and accounting for them in ration formulation. In: CORNELL NUTRITION CONFERENCE FOR FEED MANUFACTURERS, 59., 1997, Ithaca.Proceedings... Ithaca: Cornell University, 1997. p.1-10.

MORAES, E.H.B.K. Suplementos múltiplos para recria e terminação de novilhos mestiços em pastejo durante os períodos de seca e transição seca-águas. Viçosa, MG: Dissertação (Mestrado em Zootecnia) - Universidade Federal de Viçosa, 2003.

NATIONAL RESEARCH COUNCIL - NRC. Nutrient requirements of dairy cattle. 7.ed Washington, D.C.: National Academy Press, 2001. 381p.

OBEID, J.A.; GOMIDE, J.A.; SILVA, J.F.C. Efeito de níveis de uréia e do manejo da alimentação sobre o consumo alimentar e o ganho de peso de novilhos Zebu em confinamento. Revista Sociedade Brasileira de Zootecnia, v.9, n.3, p.484-493, 1980.

OLIVEIRA, A.S.; VALADARES, R.F.D.; VALADARES FILHO, S.C. et al. Produção de proteína microbiana e estimativas das excreções de derivados de purinas e de uréia em vacas lactantes alimentadas com rações contendo diferentes níveis de compostos nitrogenados não-protéicos. Revista Brasileira de Zootecnia, v.30, n.5, p.1621-1629, 2001.

OLIVEIRA, S.R. Desempenho e característica de carcaça de novilhos Nelores não-castrados. Viçosa, MG: Universidade Federal de Viçosa, 1998. 58p. Dissertação (Mestrado em Zootecnia) - Universidade Federal de Viçosa.

PELL, A.N.; SCHOFIELD, P. Computerized monitoring of gas production to measure forage digestion in vitro. Journal of Dairy Science, v.76, p.1063-1073, 1993

RENNÓ, L.N. Consumo, digestibilidade total e parcial, produção microbiana, parâmetros ruminais e excreções de uréia e creatinina em novilhos alimentados com dietas contendo quatro níveis de uréia ou dois de proteína. Viçosa, MG: Universidade Federal de Viçosa, 2003. 252p. Tese (Doutorado em Zootecnia) - Universidade Federal de Viçosa, 2003.

ROCHA, E.O.; FONTES, C.A.A.; PAULINO, M.F. et al. Ganho de peso, eficiência alimentar e característica da carcaça de novilhos de origem leiteira. Revista Brasileira de Zootecnia, v.28, n.1, p.148-158, 1999.
SILVA, D.J.; QUEIROZ, A.C. Análise de alimentos (métodos químicos e biológicos). 3.ed. viçosa: Editora UFV, 2002. 235p.

SILVA, F.F.; VALADARES FILHO, S.C.; ÍTAVO, L.C.V. et al Consumo, desempenho, característica de carcaça e biometria do trato gastrintestinal e dos órgãos internos de novilhos Nelore recebendo dietas com diferentes níveis de concentrado e proteína. Revista Brasileira de Zootecnia, v.31, n.4, p.1849$1864,2002$.

SILVA, L.M.; FEIJÓ, G.L.D.; THIAGO, L.R.L. et al. Desempenho e avaliação do potencial produtivo de forragens para ensilagem, por intermédio de diferentes fontes de suplementação nitrogenada. Revista Brasileira de Zootecnia, v.28, n.3, p.642-653, 1999.

SNIFFEN, C.J.; O'CONNOR, J.D.; Van SOEST, P.J. et al. A net carbohydrate and protein system for evaluating cattle diets. 2. Carbohydrate and protein availability. Journal of Animal Science, v.70, n.11, p.3562-3577, 1992.

SOUZA, V.G.; PEREIRA, O.G.; VALADARES FILHO, S.C. et al. Consumo e desempenho de bovinos de corte recebendo dietas com diferentes níveis de uréia. In: REUNIÃO ANUAL DA SOCIEDADE BRASILEIRA DE ZOOTECNIA, 39., Recife. Anais... Recife: Sociedade Brasileira de Zootecnia, 2002. (CD-ROM)

VALADARES FILHO, S.C.; MORAES, E.H.B.K.; MAGALHÃES, K.A. et al. Alternativas para otimização da utilização de uréia para bovinos de corte. In: SIMPÓSIO DE PRODUÇÃO DE GADO DE CORTE, 4., 2004, Viçosa, MG. Anais... Viçosa, MG: Universidade Federal de Viçosa, 2004. p.313-338.

VALADARES, R.F.D.; GONÇALVES, L.C.; RODRIGUEZ, N.M. et al. Níveis de proteína em dietas de bovinos. 1. Consumo e digestibilidades aparentes totais e parciais. Revista Brasileira de Zootecnia, v.26, n.6, p.1252-1258, 1997a.

VALADARES, R.F.D.; VALADARES FILHO, S.C.; GONÇALVES, L.C. et al. Níveis de proteína em dietas de bovinos. 4. Concentrações de amônia ruminal e uréia plasmática excreções de uréia e creatinina. Revista Brasileira Zootecnia, v. 26, n.6, p. 1270-1278, 1997c.

Van SOEST, P.J. Nutritional ecology of the ruminant. 2.ed. London: Constock Publishing Associates, 1994. 476p.

VELLOSO, L. Uréia em rações de engorda de bovinos. In: SIMPÓSIO SOBRE NUTRIÇÃO DE BOVINOS - URÉIA PARA RUMINANTES, 2., 1984, Piracicaba. Anais... Piracicaba: Fundação de Estudos Agrários Luiz de Queiroz, 1984. p.174-199.

VERBIC, J.; CHEN, X.B.; MACLEOD, N.A. et al. Excretion of purine derivatives by ruminants. Effect of microbial nucleic acid infusion on purine derivative excretion by steers. Journal of Agricultural Science, v.114, n.3, p.243-248, 1990.

WILSON, G.; MARTZ, F.A.; CAMPBELL, J.R. et al. Evaluation of factors responsible for reduced voluntary intake of urea diets for ruminants. Journal of Animal Science, v.41, n.5, p.1431-1437, 1975. 